\title{
Social and technical differentiation in smart meter rollout: embedded scalar biases in automating Norwegian and Portuguese energy infrastructure
}

\author{
Siddharth Sareen (10) 1,2凶
}

Within the energy geographies debate on the uneven scalar effects of energy transitions, this article addresses the under-examined, increasing intersection of automation and energy transitions. Using a comparative case of national smart meter rollouts-the deployment of distributed energy monitors whose diffusion constitutes the foundation for layering and automating energy infrastructure-it draws on two contrasting studies. One features an urban living lab during Norway's rapidly completed smart meter rollout to 2.9 million consumers; the other targets the national scale in Portugal during its recently accelerated twofifths completed smart meter rollout across six million consumers. The article identifies twin scalar biases: (i) social aspects of automation are controlled at higher scales while users are responsibilised for them at the household scale, and (ii) both control over and responsibility for technical aspects are restricted to higher scales. It empirically specifies how these scalar biases modulate socio-technical infrastructural interventions, such as smart meters. On this basis, it argues that embedding social and technical differentiation due to such scalar biases risks dehumanising technical aspects while detechnicising social aspects in this early intersection of energy transitions and automation.

\footnotetext{
${ }^{1}$ Department of Geography and Centre for Climate and Energy Transformation, University of Bergen, Bergen, Norway. ${ }^{2}$ Centre for the Study of the Sciences

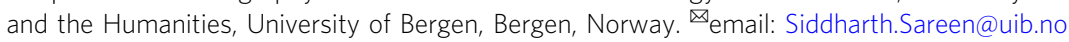




\section{Uneven scalar effects at the conjuncture of automation and energy transitions}

nergy transitions-here defined as socio-material shifts in energy systems-have uneven effects across scales. Actors negotiate the process and impact of transitioning sociotechnical infrastructures through a maze of institutional and relational factors (Rutherford and Coutard, 2014; Becker et al., 2016). Scholarship has established that these factors modulate how socio-technical interventions impact energy users, how equitable the energy sector is, and whether and how low-carbon energy transitions take place (Wolsink, 2012). The article argues that the uneven scalar effects of this modulation (Raven et al., 2012; Broto and Baker, 2018) are amplified at the conjuncture of energy transitions and forms of automation, such as smart meters, digitalisation and consumer access devices, and markets for energy flexibility. It finds that actors at lower scales (thinly distributed and at low hierarchies in the energy sector decisionmaking apparatus), such as solar prosuming households and energy communities, tend to be responsibilised for social aspects, but do not control them (cf. Larson and Ribot, 2004; Britton, 2019). Actors at higher scales (concentrated in urban conglomerations and proximate to the nerve centres that control energy sectors), such as regional utilities and traders on national energy markets, tend to be attributed technical expertise and professionalise around automation. Thus, this emerging trend at the intersection of energy transitions and automation risks dehumanising technical aspects and addressing them at higher scales, while detechnicising social aspects and placing them at lower scales.

This study defines, compares and contrasts uneven scalar effects through two cases of automation under energy transitions, namely smart meter rollout in Norway and Portugal. While smart electric meters in themselves are energy-monitoring devices, the deployment and diffusion of this distributed infrastructure at the household scale constitutes the foundation for layering and automating energy infrastructure by enabling crucial real-time digital data flows (Silvast et al., 2018). It is also thus far the part of the energy sector where digitalisation and automation have made the most empirically observable advances. This makes it a suitable focus for the research question: what scalar biases characterise the automation of socio-technical energy infrastructure?

In Norway, findings are based on an 18-month living lab, a real-world urban laboratory for experimentation characterised by "situatedness, change-orientation and contingency" (Karvonen and Van Heur, 2014, p. 379). This living lab featured 46 household sub-meter monitors that enabled users to monitor real-time household electricity consumption down to the device level, albeit patchily. It ran in parallel with Norway achieving near-universal smart meter coverage for three million consumer households, from 18 percent in January 2017 to 97 percent or 2.9 million smart meters in January 2019. It thus explored changeorientation during a time of contingency in a situated manner, centred on perspectives of household users as the targets of smart meter rollout. In Portugal, findings focus on the national scale, tracing during 2017-2019 how smart meter rollout was modulated through a top-down process (Coutinho et al., 2017) to twofifths of six million consumer households (2.4 million by September 2019). In addition, these findings reflect on the relevance of uncertainties related to distribution grid concessions, based on 5 months of fieldwork in Portugal. The first case unpacks how people comprehend the emergent technical possibilities of smart grids, but face intractable barriers to routinise individual and social engagement in shaping Norway's energy transition impacts at the local scale (Sareen and Rommetveit, 2019). The second case illustrates how the rollout of smart meters is justified in a way that has little to do with their actual social use (Gouveia and Seixas,
2016), and rather depends on technical legitimation strategies that do not fully apprehend its impacts on the Portuguese energy transition.

On this twin basis, the article studies multi-scalar modulation to identify the scalar biases of automation during energy transitions. At the household scale, it appears that users tend to be responsibilised for individual behavioural change even though this presents only nominal gains in energy efficiency. At the grid scale, it seems that incumbent utilities tend to control technical change and set terms that favour them over energy users on matters like distribution grid concessions and installing solar capacity. The article argues that such biases lower people's agency to envision and enact post-automation energy futures. Uneven scalar effects place responsibilities on these users to conform to a particular mode of sectoral evolution that maintains control in the hands of supply-side actors. Emerging configurations during smart meter rollout indicate that the main role played by actors at lower scales-such as household users-is to be responsible for some social aspects of this basic step in automation. In contrast, overall control and responsibility is largely retained by actors at higher scales, such as regulators and national and regional utilities. Empirically identifying scalar biases during transitions to automated energy infrastructure-using the emerging example of smart meters-improves our understanding of how such sociotechnical interventions are modulated in contrasting yet comparable Norwegian and Portuguese cases.

The article is structured in the following order. The next section, "Energy geographies of infrastructure transition: the scalar unevenness of automation", presents a brief literature review that connects the concept of scale, within the field of energy geographies, with scholarship on smart energy infrastructure and automation. This is followed by the section "Scales of control and responsibility in socio-technical automation", which elaborates the role of control and responsibility in the automation of a sociotechnical sector such as electricity, defines these key concepts, and proposes an analytical framework for the article. Thereafter, the section "Methodology and background: case selection and data" explains the basis for case selection and data collection. It provides basic background details for the two contrasting cases, including the household electricity infrastructure context, the smart meter rollout trajectories in Norway and Portugal, and the data sources used.

Next, an empirically informed section "Findings and analysis: scales of control and responsibility" briefly analyses the two cases of socio-technical automation. It argues that lower scale actorsusers-are excluded from both control and responsibility for technical aspects, and that the automation of energy infrastructure is primarily treated as a technical matter for experts at hierarchies above the household scale. This provides the basis for the conclusion. The final section, "Embedding social and technical differentiation in the automation of energy infrastructure", discusses the scalar unevenness of automation in terms of where control over and responsibility for the social and technical aspects of automation are located in each case. It is concluded that these scalar biases limit the social imaginaries of what smart meter rollouts can and do enable in terms of smart electric grids of the future.

\section{Energy geographies of infrastructure transition: the scalar unevenness of automation}

In recent years, energy geographies has emerged as a distinct field of scholarship that analyses how geographies determine societies' interactions with their energy systems (Huber, 2015). This field is responsive to the pressing concern of an urgent transition to lowcarbon energy systems. Such a transition can mitigate the worst 
effects of runaway climate change by lowering this component of greenhouse gas emissions. As a discipline, geography is equipped to theorise the scalar unevenness of energy transitions, which play out in socio-material geographies that are often characterised by the spatial concentration of power and control over energy systems in urban centres, close to where political power is also held (Broto and Baker, 2018; also see Evans et al., 2019). The field seeks to direct attention to the socio-spatially marginalised areas and populations who are most vulnerable to and least able to influence energy transitions as they unfold. It combines attention to issues of structure and agency at and across multiple scales, both horizontal (spatial) and vertical (hierarchies of power), with an appreciation of the socio-materiality of energy infrastructure itself (Bulkeley et al., 2016; Sareen and Haarstad, 2018).

Increasingly, one of the main ways in which scholars, policymakers, planners and practitioners discuss the socio-materiality of low-carbon energy transitions is in terms of increasing automation (Adil and Ko, 2016; Lund et al., 2017). Smart city debates address energy sector automation at the urban scale (Luque-Ayala and Marvin, 2019; Britton, 2019), and regional debates are concerned with its implications for network infrastructure (Hall and Foxon, 2014). Spatiotemporal concerns around energy flexibility are rife in technical scholarship (Lund et al., 2017); business models are evolving to capitalise on the opportunity posed by cost declines in energy storage and renewable energy sources through new algorithms and energy data infrastructures for dynamic pricing (Hashem et al., 2016). A question arises whether these changes will reconfigure prevalent energy supply logics (Eid et al., 2016). Nowhere is this more keenly relevant than in societal debates about smart meters, which have excited interest and proved contentious (Sareen and Rommetveit, 2019; Stephens et al., 2013). Analysing smart meter rollouts can thus serve as a window onto the politics and governance of urban experimentation (Bulkeley et al., 2014; Hodson and Marvin, 2015). There have been recent efforts to do so through urban living lab approaches (e.g., McLean et al., 2016), as well as comparative analyses of contrasting rollouts at national scales (e.g., Silvast et al., 2018).

A smart meter is a specific data infrastructure that comes with the promise of improved monitoring and greater energy flexibility on the electric grid (Hledik, 2009). The past decade has seen increasing interest in such promises, and many countries, notably in Europe but also others such as the USA and China, have commenced smart meter rollout at the national scale. Some such programmes are even close to completion, one example being Norway. Household users (whom this article is concerned with) have been the main focus of such rollout programmes, since larger users have typically already had smart meters installed. As a socio-technical intervention, the rollout has involved installing new devices in every household at the point where the electric grid delivers electricity to the household. The capabilities of the new, so-called smart meters vary across and even within countries -as a general minimum, a digital screen displays the total amount of energy consumption in kilo watt hours (kwh), with additional functionalities all the way to enabling users to access their real-time electricity consumption via smartphone applications (Benzi et al., 2011). Suppliers also gain access to these data, with one of the common justifications of such rollouts being that this enables suppliers and distribution service operators (DSOs) to manage energy supply more efficiently (Erlinghagen et al., 2015). The granular monitoring of real-time consumption can also facilitate the creation of new value streams, including demand-side flexibility and Internet-of-Things functionalities (cf. Stojkoska and Trivodaliev, 2017). Questions abound, such as whether the benefits of prospective efficiency gains will be shared with users, and whether smart meters can enable sophisticated future demand response (Schick and Gad, 2015; Saele and Grande, 2011)-i.e., the management of user demand to help electric utilities balance the load on the grid, which has traditionally been done by adjusting electric supply rather than demand.

Thus, despite smart meters being energy infrastructure that is put in place at the household scale, their effect as a socio-technical intervention that builds automation into transitioning energy sectors spans multiple scales (Wolsink, 2012; Britton, 2019). While smart meters specifically automate data collection, this constitutes a foundational step to enable the remote and real-time control of energy demand and appliances (cf. Silvast et al., 2018). Future flexibility business models can build on this infrastructure to use data and controls through consumer access devices (e.g., smartphone applications, cf. Sareen and Rommetveit, 2019) and emerging Internet-of-Things devices (cf. Alaa et al., 2017). Uneven scalar effects may come into play with regard to spatial considerations of how the digitalisation and monitoring of realtime distributed and disaggregated consumption data affects energy sector stakeholders, and in terms of how households, suppliers and utilities are positioned along vertical scales or hierarchies of decision-making to access and act upon these data infrastructures and flows (Bulkeley et al., 2016; Schick and Gad, 2015; Sareen et al., 2020). It is clear, then, that smart meter rollouts constitute interventions that act upon the ontology of existing energy sectors and build automation into infrastructure.

Despite this recognition, smart meter rollouts have only begun to be analysed in these terms in emergent, empirical energy geographies scholarship and across multiple scales. This timely research need deserves to be more fully addressed, precisely because of the insights from energy geographies on the significance of uneven scalar effects. The modalities of building automation into the socio-materiality of critical energy infrastructures have consequences for how user-centric and democratic an energy future such infrastructures enable (Stephens et al., 2013; Szulecki, 2018). To analyse automation in sociotechnical transitions, this article unpacks the impact of uneven scalar effects-or in other words, scalar biases-during smart meter rollout.

\section{Scales of control and responsibility in socio-technical automation}

Energy infrastructure is socio-technical in nature. Energy use is inherently social, as it is deeply embedded into social practices and behaviours shaped and conditioned by interactions with evolving energy infrastructure over time (Shove et al., 2015; Schivelbusch, 1995). Energy infrastructure is also deeply technical, as its design and management requires expert handling of the complexities of balancing shifting patterns of energy supply and demand over time and space. The average household user of an electric grid lacks a detailed understanding of technical aspects of energy infrastructure, while embodying a specific everyday social relationship with this infrastructure (Sareen and Rommetveit, 2019). Any society features a range of such everyday relationships, which can be categorised along lines such as a household's ability to afford electricity; residential buildings typologies and their energy needs; house ownership and consequent control over energy and other infrastructure; and intra-household power dynamics among inhabitants (Gouveia and Seixas, 2016; Grossmann, 2019). Most utility workers who have a detailed understanding of the technical aspects of an electric grid lack insight into the variety of everyday relationships users have with it (Naus et al., 2014; Katzeff and Wangel, 2015). Their assumptions about the way households use electric infrastructure are plausibly founded on their own experience with it as users, combined with 
Table 1 Control and responsibility in a multi-scalar socio-technical transition.

Social aspects

Control

Responsibility
Which user and at what scale?

Which user and at what scale?
Technical aspects

Which user and at what scale?

Which user and at what scale? stories from media reports, from their friends and colleagues, and from grey literature on the sector (Ballo, 2015; Skjølsvold et al., 2015). There is thus a broad clustering of insights: on the social aspects of this socio-technical infrastructure at the household scale, and its technical aspects at the utility scale.

It follows from the above that, as a socio-technical intervention that seeks to build automation into electric grids, the rollout of smart meters takes place in a field that exhibits uneven scalar effects. Utilities are more knowledgeable about technical aspects whereas households are better versed with social aspects of electric grids as an everyday infrastructure. Thus, smart meter rollout can be construed in terms of control over and responsibility for each of its aspects, the social and technical. Who has control over each aspect, and who is responsible for it? At what scales are control and responsibility exercised? This is depicted as a $2 \times 2$ matrix in Table 1 .

This matrix provides the analytical approach deployed to analyse two cases in this article. The term 'control' is defined in relation to extensive debates in science and technology studies (STS) scholarship. On the one hand, components of energy systems can be controlled (usually centrally), whereas components outside energy systems comprise the general environment and cannot be controlled (Hughes, 1983; Rohracher, 2008). On the other hand, energy infrastructure can be regarded as webs where control is more spatially distributed and exercised through networks of relations (Edwards, 2010; Silvast et al., 2013). In this article, control refers to the ability to exercise power in favour of a particular configuration of energy infrastructure and its effect on the overall energy system. The term 'responsibility' is defined in relation to political ecology scholarship on decentralised governance and accountability (Larson and Ribot, 2004; Agrawal and Ribot, 1999). It refers to obligations by actors who are held accountable for a certain object, such as a process or infrastructure: in this case the smart meter. As these scholars of governance and power have established, responsibility is not always accompanied by power (which is associated with control, as defined above), but the relations of responsibility that are established confer legitimacy to the exercise of power in a particular configuration by specific actors. Thus, control and responsibility provide an analytical framework to identify how power is exercised, by whom and at what scales.

The next section describes the case selection and data collection. It also provides background details for both cases. Based on empirical findings for the smart meter rollout cases in Norway and Portugal, the section "Findings and analysis: scales of control and responsibility" argues that specific, similar patterns are discernible in both interventions. The conclusion operationalises the analytical framework explicated above. It abstracts out from this analysis to discuss socio-technical differentiation in the embedment of scalar biases during the emergence of automation of energy infrastructure. It concludes by reflecting on the implications for larger energy sector transitions, in terms of the conditions such scalar biases and socio-technical differentiation may bring into place for electric grids of the future.

\section{Methodology and background: case selection and data}

The smart meter rollouts in Norway and Portugal have been selected to maximise difference (Lijphart, 1975). They are different in at least three ways: empirical data sources and their scalar locations used for this article; household electricity infrastructure context; and the trajectory and degree of each rollout. This provides a rich comparative dataset combined in a manner that the qualitative research community in energy social science is pushing for (cf. Middlemiss et al., 2020).

Empirical data sources and their scalar locations. For Norway, this article draws on empirical data from an urban living lab on smart grids, as part of the PARticipatory platform for sustainable ENergy managemenT (PARENT) project (see https://www. parent-project.eu). This ran for 18 months during 2017-2019 with 46 purposively sampled households in Bergen in parallel with smart meter rollout, with a focus on social imaginaries of this infrastructural change. Using a sub-meter monitor in each household to simulate a sophisticated smart meter, the living lab generated real-time device-level electricity usage data (Sareen and Rommetveit, 2019). This was available to living lab participants and project staff. Data collection was accompanied by monthly newsletters on energy behaviour and an online (web browser and smartphone application based) platform for users to track their real-time usage, patterns over time, and to compare usage with similar-sized households. Methods included iterative meetings for three rounds of focus group discussions; a few individual interviews; surveys at the beginning and end of the living lab; and a workshop with the living lab participants where the sub-meter monitor was physically deconstructed as a basis for discussion. This empirical material provides a basis to understand household behaviour and perceptions, including participants' reflections on the political economy and socio-technical aspects of smart meters. The author was part of the project team that ran the urban living lab. As these results have been reported in greater detail elsewhere (cf. Sareen and Rommetveit, 2019), this article summarises key findings drawn from the extensive data in relation to the scalar aspects of automating socio-technical infrastructure.

For Portugal, the article draws on a subset of data from 80 interviews with energy sector experts, as well as field observations at energy sector meetings and projects conducted by the author for 5 months during 2017-2019. These ethnographic data collection techniques were mainly focused on energy transitions in relation to solar energy uptake at multiple scales (cf. Sareen and Haarstad, 2018; Sareen, 2020), with smart meters studied as a cognate concern. As the interviews were in-depth (50-150 min) and semi-structured, the close links between smart meters and solar PV rollout (cf. Pereira et al., 2018) meant that smart meters were referred to frequently. Smart meters were discussed with over 20 experts in 15 of these interviews, complemented by site visits to smart meter pilot projects, including the flagship EDP Inovgrid project. In contrast to Norway, the methods in Portugal generated insights at the national and sub-national scale, e.g., in the Evora township where EDP ran the pilot project Inovgrid with over 30,000 households. Interviewees included representatives from: the DSO EDP which is also an energy supplier, the national electricity regulator, the national executive authority for energy, energy consultants, regional sectoral researchers, an energy cooperative, journalists, investors, regional agencies, and municipalities of various sizes, including the national capital Lisbon. 
Household electricity infrastructure context. Norwegian electricity is largely sourced from hydropower, which dominates domestic electricity production, supplemented by a little wind energy in the grid mix. In 2018, hydropower was 95 percent and wind 3 percent of the Norwegian electricity source mix, leaving a minimal role for fossil fuel sources (IEA, 2019). The materiality of hydropower makes energy generation distant from most electricity users, and offers grid flexibility due to Norway's landscape, which lends itself to reverse hydro pumping as an energy storage technology (Hagos et al., 2014). Given this plentiful and relatively clean electricity source, households in Norway power much of their household energy needs with electricity, including typical electric appliances (lighting, white goods like washing machines and dishwashers), electric stoves and ovens for cooking, electric water and space heating (Nesbakken, 1999), and most recently rapid growth in electric vehicle charging. Electricity consumption expenditure constitutes a relatively small share of household disposable income, and while there is little by way of data on energy poverty for Norway, this lack of data despite a generally sophisticated national statistics system itself symbolises the relative abundance of household electricity access and affordability.

Portugal is one of the leading European countries on renewable energy sources for electricity. In 2018, 52 percent of its grid mix was supplied by hydropower, wind, solar, geothermal, biofuels and biomass energy sources; fossil fuels such as coal, oil and gas make up an increasingly smaller portion (Gouveia et al., 2014; IEA, 2019). This currently enables it to balance the grid relatively easily, but with an envisaged increase in renewable energy penetration to transition to fully renewable electricity sources by 2030 , energy flexibility is a current concern. Households rely on electricity mainly for lighting and some for white goods, whereas cooking is often powered by gas. Space heating is based on a variety of sources including electricity to a very limited extent, while water heating is often solar thermal due to high irradiation rates, or electric. The country has one of Europe's highest energy poverty rates (Gouveia and Seixas, 2016), and features a growing focus on alleviating this through measures, such as a social electricity tariff for energy poor households (Horta et al., 2019). Users are generally conscious of their electricity bills as this constitutes a significant expense compared to household income, and the use of electricity is spartan compared to Norway (cf. Horta et al., 2019; Mills and Schleich, 2012).

Trajectory and degree of rollout. Norway's smart meter rollout to 2.9 million out of three million consumers was decided upon in 2011, despite a negative result from an initial cost benefit analysis (Ballo, 2015), with the completion deadline postponed from 2017 to 2019 in 2013. It is an example of close government-industry coordination, where industrial actors undertook early research and development and held a close dialogue with the national regulator to agree upon a supply-side process and timeline (Inderberg, 2015). Deployment stood at 18 percent by the end of 2016, and 2 years later, reached 97 percent nationwide, at about 10 percent below the initial cost estimate, and costing about $€ 300$ per smart meter (based on official data displayed on www.nymaler.no as of 13.03.2020). It was executed by over 130 DSOs (some have since been consolidated, but as of 2020 Norway had over 120 DSOs), and followed a mandatory model with limited opt-out possibilities and hefty penalties (exceeding €200) for dissenting users. This makes it one of the fastest and smoothest rollouts for any national programme. But it was not altogether free of controversy, with 0.3 percent of users refusing to allow utilities physical access to install smart meters, or acquiring medical certificates to exempt themselves on grounds of health concerns, as evident with the formation of organisations, such as http://stoppsmartmaalerne.no (literally Stop Smart Meters) and Facebook protest groups with thousands of members.

By contrast, Portugal began its smart meter rollout with an urban-scale pilot across more than 30,000 households in the town of Evora in 2009. This was in place relatively early, with monitoring of household energy savings (for details, see Guerreiro et al., 2015). The utility, Energais de Portugal (EDP), established a demonstration facility called Inovgrid to showcase the potential benefits of smart grids as a flagship case in Europe. By 2015, EDP had deployed over 100,000 smart meters, replicating its Inovgrid experience at six other sites. Unlike Norway with over 120 DSOs, the incumbent DSO EDP dominates mainland electricity distribution in Portugal. The national regulator incentivised rollout by providing a premium rate of return for investments in energy efficiency-enhancing infrastructure (including smart meters), but did not allow the DSO to recover costs directly from users. Due to an initially inconclusive cost-benefit analysis in 2012, and despite a positive one in 2015, the regulator did not establish a national target. Despite this, deployment began to accelerate during 2017, when 600,000 smart meters were installed. Total deployment reached 25 percent by the end of 2018 , then exceeded 40 percent with 2.5 million smart meters installed by September 2019, as per media reports. More precise figures were not available due to the lack of official reporting requirements or a national programme. While users had a right to access their data, the smart meters were owned (unlike in Norway) by the DSO.

\section{Findings and analysis: scales of control and responsibility}

The analytical framework was applied to these contrasting cases in order to examine the scalar biases that characterise the automation of socio-technical energy infrastructure in each of them.

Norway. Living lab participants encountered a number of problems during all stages of the rollout, which simulated actual smart meter deployment. Problems began with the installation, when different legacy infrastructures (the type of existing electricity meter and switchboard and its physical location within or outside the residential building) modulated how smooth or frustrating participants found the process. Problems extended to the lack of ease participants experienced in using the smartphone application to access their real-time electricity usage data. The algorithm used by the sub-meter monitor was clunky in being able to pick up some devices; for instance, electric stoves (where each intensity setting pulls different amounts of electricity) showed up as many individual devices. While some participants found it interesting to track their electricity usage patterns (daily peaks and troughs, daily demand curves over the months), others reported that their interest dwindled quickly and they did not engage regularly with the smartphone application or an interactive online platform (which was gamified to compare their consumption with similar households).

Beyond these practical traits, participants reported numerous concerns: some did not feel they could trust the energy companies with data on their electricity usage; others felt Norway's investments for energy flexibility were only helping other countries (for instance to reduce Germany's dependence on coal) while burdening Norwegian taxpayers. Participants' keenness and ability to reduce their own electricity consumption based on the smart meter simulation varied, but they shared a common sense of disenfranchisement-they were not able to influence the way smart meters were being rolled out or what it meant for their energy future or how their data were used or abused (also see Sareen and Rommetveit, 2019). These participants were all 
purposively sampled based on their interest in the energy sector and, being part of a technologically sophisticated pilot, many were tech savvy and knowledgeable, and some were early adopters of solar panels and electric vehicles, so such a sentiment coming from them is notable. If these relatively informed and affluent households felt marginalised in decision-making on the modalities of smart meter rollout and what it meant for household energy futures, what scope is there to secure the concerns of the average person?

Alongside the living lab, the smart meter rollout was completed in Norway, with over 97 percent coverage by January 2019. By February 2020, the national platform Elhub was operational. This enabled continuous exchange of real-time energy usage data among validated actors registered on Elhub, thus providing a basis for supply-side energy efficiency gains and further automation, including Internet-of-Things applications for demand-side flexibility. It remained to be seen to what extent future automation innovation, driven by supply-side interests, would benefit users.

Portugal. Respondents in Portugal saw smart meter rollout as a deeply contingent process. Energy researchers pointed out that public perception that smart meters would increase costs made rollout difficult for the DSO, which had to invest in deploying this infrastructure. For the DSO, EDP, smart meters were an important technical addition to the low voltage distribution network, which would improve detailed data flow and analysis. The Inovgrid pilot project made it clear that there were supply-side advantages. But without regulatory permission to gradually recover most rollout costs via fixed charge components of consumers' electricity bills, the rapid progress of the rollout was uncertain even to sectoral actors. An EDP representative found various regulatory limits frustrating, as the DSO could not install customised infrastructure at the transformer (household cluster) scale, which could have opened up scope for greater supply-side flexibility and gains in efficiency. A regulatory representative explained the necessity of imposing this limit. This was namely to avoid favouring a particular utility, as the distribution grid license was given to the DSO for a fixed period by the 308 municipalities in Portugal, which hold the right to distribute electricity within their territory.

While EDP had been given this right during the liberalisation of Portugal's electricity sector in the mid-2000s, it was up for renewal. During 2018 and 2019, the design of the concessions for the distribution grid was the subject of technical discussions, and also of parliamentary debates. The latter revolved around the basis on which to value this infrastructure, given the uncertainties that surrounded how smart electric grids would be used in coming decades. The ability to control electric flows would increase in value, due to the need for greater energy flexibility as low-carbon energy sources would grow and sectors like transport would be electrified. A respondent with technical insight into the electricity sector in Portugal mused that control over the distribution grid infrastructure was a 'cash cow' for the DSO. Yet the DSO was one of the expert entities who provided inputs to the regulator's decision on how to design the distribution grid concessions: as a small number of large municipal groups. EDP representatives saw this as natural, since they were best positioned to give such technical inputs. But a Ministry of Environment and Energy Transition, formed in October 2018, wanted a clearer process, and delayed grid concessions until 2020. This prolonged the uncertainty of long-term grid control for the DSO, which nonetheless proceeded to deploy smart meters, ostensibly expecting to be able to win licences in most if not all of Portugal.
A consultant with long-term knowledge of national regulation mused that, despite months of debates, public and sectoral discussions had not dealt with smart grids at all. At a June 2019 national meeting, a researcher pointed to other countries' experiences with distribution grid concessions to suggest that a far larger number of territories with many companies competing over the DSO licences in a regulated monopoly at the regional scale would be favourable for Portugal, citing Sweden and Norway as examples. These charged events at the national scale showed concern about the technical uncertainties and the necessity of establishing a value for distribution grid infrastructure in line with an evolving understanding of energy flexibility. But there was no mention of social aspects of smart meter rollout as a socio-technical intervention. By 2020, EDP had launched its 'EDP re:dy box'. This promoted smart meters with accessories that consumers could buy to enable Internet-of-Things functions such as remote control of home energy devices, creating new value streams that EDP was well positioned to benefit from. Smart meters were thus successfully branded as a centrally delivered technical innovation rather than a potential gamechanger for the dynamics of control over energy infrastructure due to automation.

\section{Embedding social and technical differentiation in the automation of energy infrastructure}

The contrast in focus at the household scale and the national scale is revelatory. It is summarised in Table 2. Empirical material on Norway was focused on the household scale, but literature was also available about the national scale. Empirical material on Portugal was collected at the national scale, but conveyed clear indications of prospects for the household scale as the rollout progressed. Despite various contrasts between the two cases, they show remarkable similarity: control for both social and technical aspects rests predominantly at the national scale; responsibility for social aspects is placed at the household scale; and responsibility for technical aspects remains at the national scale.

To discuss this based on the analysis above: living lab participants in Norway felt responsibilised to manage the social aspects of smart meters themselves (or at least of the simulator, which closely mirrored such an intervention almost simultaneous to the actual rollout). The complexity of these social aspects was poorly represented in the national discussion, which only incorporated debate on health and privacy concerns to a limited extent, even as households were forced to accept the intervention (Ballo, 2015; Inderberg, 2015). In Portugal, social aspects were essentially missing from the debate, which remained limited to technical matters and largely outside the public eye, since the rollout was not mandatory and the DSO absorbed the costs. Yet households were forced to accept infrastructural automation wherever the DSO chose to roll it out. By contrast, control over how to roll out smart meters, what characteristics to mandate, and how they should interface with energy use, remained firmly at the national scale in both countries. Household participants felt excluded from any real influence on this in Norway (Sareen and Rommetveit, 2019), whereas in Portugal, control remained with experts; it was not regarded as part of a broader social concern.

\begin{tabular}{|c|c|c|}
\hline & Social aspects & Technical aspects \\
\hline Control & National scale & National scale \\
\hline Responsibility & Household scale & National scale \\
\hline
\end{tabular}


In both countries, control over technical aspects was maintained at the national scale, without any representation from the household scale. Technical aspects were moreover seen as the responsibility of national scale actors-they were dealt with in a centralised manner, by regulators, ministries and large utilities (in Norway, this included the industry association Energy Norway, cf. Inderberg, 2015), rather than with a role for actors at disaggregated scales to participate in and shape discussions and regulations. While this is understandable for complex technical parts of large infrastructure systems, smart meters are at the supply-demand interface and an example of energy infrastructure that households can and do interact with. Thus, this exclusion of lower scales from both control and responsibility for technical aspects limits the social imaginaries of what smart meter rollout can and does enable in terms of smart grids of the future.

The findings and analysis above, when fitted into Table 2, surface an uneasy relationship between automation in sociotechnical transitions and the uneven scalar effects of energy geographies. Despite being contrasting socio-economic contexts in which electric grids serve distinct needs, and despite featuring smart meter rollout programmes that have been designed and fared in different ways, Norway and Portugal have a lot in common when it comes to the user-centric and democratic nature of their smart meter rollouts, or lack thereof. It seems fair to say that there is a prevalent view in both countries that favours smart meters rollout, so this article does not intend to challenge that choice. But in representative democracy, the question of how to do what most people agree should be done is tremendously important (cf. Larson and Ribot, 2004). This is a matter of process legitimacy, and social legitimacy, and the analysis put forward supports the argument that both rollouts fall short on these fronts (also see Jegen and Philion, 2017). They are characterised by scalar biases that reduce the role of households as smart meter users to responsibilised recipients of socio-technical interventions, whose behaviour and everyday use of electric grids has to fall in line with decisions made at the national scale. The actual manner of deployment and what the socio-technical energy infrastructure should do and actually does are treated as technical matters for experts at hierarchies above household scales.

In practice, this reduces uncertainty and makes the sociomaterial advent of automation in energy transitions a largely technical matter that falls within a stable social imaginary of what energy infrastructure should do within what our current energy system looks like (Sareen and Rommetveit, 2019). Rollout that privileges the scalar biases of technical decision-making at national scales neither enables a deliberative consensus-building process across multiple scales (Britton, 2019), nor recognises the socio-technical complexities and possibilities inherent in introducing infrastructure like smart meters (Sareen and Haarstad, 2018). It simply goes ahead with implementing a pre-defined vision that is determined by the understanding and interests of experts up the hierarchy of bureaucratic energy sectors. The Norwegian case shows that this can proceed relatively smoothly and effectively through early government-industry coordination; the Portuguese example shows that while lack of clarity can slow things down, it can be dealt with among technical and political experts, and resolved without bringing in greater user perspectives.

The challenging option, rich with uncertainties and possibilities, is one that requires an appetite for and genuine interest in the ways people think, feel and interact with energy infrastructure (Evans et al., 2019). But decision-makers at the national scale operate under constrained conditions. They require an exceptional outlook to perceive the value of reflexive policy processes, and great political will to cultivate them over time (Becker et al., 2016;
Broto and Baker, 2018). The evidence from how energy transitions have fared so far suggests poor chances of such attitudes and efforts pushing towards user-centric automation that provides greater control to the household scale or even urban administrators (cf. Britton, 2019)-smart meter rollout as the emerging first layer to enable advanced socio-technical automation is no exception.

Creating space for deliberation-expending political capital to argue for more measured, painstaking approaches-is an essential component of efforts to overcome the uneven scalar effects of socio-technical interventions (Evans et al., 2019; Raven et al., 2012). Yet, consensus orchestrated among a few key players by offering everyone who already has a seat at the table something to satisfy their interests is easier, and often sufficiently convincing to secure social and process legitimacy in energy sector governance arrangements (cf. Jegen and Philion, 2017; also see Agrawal and Ribot, 1999). The study of two contrasting country cases adds empirical weight to this short-sighted trend. The historical perception of electricity as a largely technical sector allows the automation of energy infrastructure to proceed in largely technical and top-down ways precisely because it matches the prevalent social imaginary, despite its clear and increasing impact on everyday social practices.

\section{Data availability}

The interviews analysed during this study are not publicly available due to the sensitive nature of thematic qualitative data and their use in other outputs as part of two recent and ongoing projects; however, suitably anonymised notes on specific institutionally attributed interviews are available from the corresponding author on reasonable request.

Received: 9 December 2019; Accepted: 16 June 2020; Published online: 08 July 2020

\section{References}

Adil AM, Ko Y (2016) Socio-technical evolution of decentralized energy systems: a critical review and implications for urban planning and policy. Renew Sustain Energy Rev 57:1025-1037

Alaa M, Zaidan AA, Zaidan BB, Talal M, Kiah MLM (2017) A review of smart home applications based on Internet of Things. J Netw Comput Appl 97:48-65

Agrawal A, Ribot JC (1999) Accountability in decentralization: a framework with South Asian and West African cases. J Dev Areas 33(4):473-502

Ballo IF (2015) Imagining energy futures: sociotechnical imaginaries of the future smart grid in Norway. Energy Res Soc Sci 9:9-20

Becker S, Beveridge R, Röhring A (2016) Energy transitions and institutional change: between structure and agency. In: Gailing L., Moss T. (eds) Conceptualizing Germany's Energy Transition. Palgrave Pivot, London, pp. 21-41

Benzi F, Anglani N, Bassi E, Frosini L (2011) Electricity smart meters interfacing the households. IEEE Trans Ind Electron 58(10):4487-4494

Britton J (2019) Smart meter data and equitable energy transitions: can cities play a role? Local Environ 24(7):595-609

Broto VC, Baker L (2018) Spatial adventures in energy studies: an introduction to the special issue. Energy Res Soc Sci 36:1-10

Bulkeley H, McGuirk PM, Dowling R (2016) Making a smart city for the smart grid? The urban material politics of actualising smart electricity networks. Environ Plan A: Econ Space 48(9):1709-1726

Bulkeley HA, Broto VC, Edwards GA (2014) An urban politics of climate change: experimentation and the governing of socio-technical transitions. Routledge

Coutinho B, Ferreira É, Pena R, Nunes V (2017) Enhancing stakeholders involvement by smart meters deployment campaign. CIRED-Open Access Proc J 2017(1), 2736-2739

Edwards P (2010) A vast machine: computer models, climate data, and the politics of global warming. MIT Press, Cambridge

Eid C, Hakvoort R, de Jong M (2016) Global trends in the political economy of smart grids: a tailored perspective on 'smart' for grids in transition (no. 2016/ 22). WIDER working paper $2016 / 22$ 
Erlinghagen S, Lichtensteiger B, Markard J (2015) Smart meter communication standards in Europe-a comparison. Renew Sustain Energy Rev 43:1249-1262

Evans J, Karvonen A, Luque-Ayala A, Martin C, McCormick K, Raven R, Palgan YV (2019) Smart and sustainable cities? Pipedreams, practicalities and possibilities. Local Environ 24(7):557-564

Gouveia JP, Dias L, Martins I, Seixas J (2014) Effects of renewables penetration on the security of Portuguese electricity supply. Appl Energy 123:438-447

Gouveia JP, Seixas J (2016) Unraveling electricity consumption profiles in households through clusters: combining smart meters and door-to-door surveys. Energy Build 116:666-676

Grossmann K (2019) Using conflicts to uncover injustices in energy transitions: the case of social impacts of energy efficiency policies in the housing sector in Germany. Glob Transit 1:148-156

Guerreiro S, Batel S, Lima ML, Moreira S (2015) Making energy visible: sociopsychological aspects associated with the use of smart meters. Energy Effic 8(6):1149-1167

Hagos DA, Gebremedhin A, Zethraeus B (2014) Towards a flexible energy system -a case study for Inland Norway. Appl Energy 130:41-50

Hall S, Foxon TJ (2014) Values in the smart grid: the co-evolving political economy of smart distribution. Energy Policy 74:600-609

Hashem IAT, Chang V, Anuar NB, Adewole K, Yaqoob I, Gani A, Chiroma H (2016) The role of big data in smart city. Int J Inf Manag 36(5):748-758

Hledik R (2009) How green is the smart grid? Electr J 22(3):29-41

Hodson M, Marvin S (eds) (2015) Retrofitting cities: priorities, governance and experimentation. CRC Press

Horta A, Gouveia JP, Schmidt L, Sousa JC, Palma P, Simões S (2019) Energy poverty in Portugal: combining vulnerability mapping with household interviews. Energy Build 203:109423

Huber M (2015) Theorizing energy geographies. Geogr Compass 9(6):327-338

Hughes T (1983) Networks of power: electrification in Western Society, 1880-1930. Johns Hopkins University Press, Baltimore

IEA (International Energy Agency) (2019) Electricity information 2019: statistics report. IEA, Paris. https://www.iea.org/reports/electricity-information-2019. Accessed 13 Mar 2020

Inderberg TH (2015) Advanced metering policy development and influence structures: the case of Norway. Energy Policy 81:98-105

Jegen M, Philion XD (2017) Power and smart meters: a political perspective on the social acceptance of energy projects. Can Public Adm 60(1):68-88

Karvonen A, Van Heur B (2014) Urban laboratories: experiments in reworking cities. Int J Urban Reg Res 38(2):379-392

Katzeff C, Wangel J (2015) Social practices, households, and design in the smart grid. In: Hilty L., Aebischer B. (eds) ICT innovations for sustainability. Springer, Cham, pp. 351-365

Larson AM, Ribot JC (2004) Democratic decentralisation through a natural resource lens: an introduction. Eur J Dev Res 16(1):1-25

Lijphart A (1975) II. The comparable-cases strategy in comparative research. Comp Political Stud 8(2):158-177

Lund H, Østergaard PA, Connolly D, Mathiesen BV (2017) Smart energy and smart energy systems. Energy 137:556-565

Luque-Ayala A, Marvin S (2019) Developing a critical understanding of smart urbanism. In: Schwanen T., van Kempen R. (eds) Handbook of urban geography. Edward Elgar Publishing, pp. 201-224

McLean A, Bulkeley H, Crang M (2016) Negotiating the urban smart grid: sociotechnical experimentation in the city of Austin. Urban Stud 53(15): 3246-3263

Middlemiss L, Straver K, Hesselman M, Tirado Herrero S, Feenstra M, Hargreaves T, Meyer S, O'Sullivan K, Sareen S, Thomson H (2020) Making the most of qualitative evidence for energy poverty mitigation: a research agenda and call for action. European Energy Poverty: Agenda Co-Creation and Knowledge Innovation (ENGAGER 2017-2021) Policy Brief 3, February 2020. www. engager-energy.net/wp-content/uploads/2020/02/ENGAGER-Policy-BriefNo.-3-February-2020-Making-the-Most-of-Qualitative-Data-for-EPResearch-and-Action.pdf. Accessed 13 Mar 2020

Mills B, Schleich J (2012) Residential energy-efficient technology adoption, energy conservation, knowledge, and attitudes: an analysis of European countries. Energy Policy 49:616-628

Naus J, Spaargaren G, van Vliet BJ, van der Horst HM (2014) Smart grids, information flows and emerging domestic energy practices. Energy Policy 68:436-446

Nesbakken R (1999) Price sensitivity of residential energy consumption in Norway. Energy Econ 21(6):493-515

Pereira GI, Specht JM, Silva PP, Madlener R (2018) Technology, business model, and market design adaptation toward smart electricity distribution: Insights for policy making. Energy Policy 121:426-440

Raven R, Schot J, Berkhout F (2012) Space and scale in socio-technical transitions. Environ Innov Soc Transit 4:63-78
Rohracher H (2008) Energy systems in transition: contributions from social sciences. Int J Environ Technol Manag 9(2):144-61

Rutherford J, Coutard O (2014) Urban energy transitions: places, processes and politics of socio-technical change. Urban Stud 51(7):1353-1377

Saele H, Grande OS (2011) Demand response from household customers: experiences from a pilot study in Norway. IEEE Trans Smart Grid 2(1):102-109

Sareen S, Haarstad H (2018) Bridging socio-technical and justice aspects of sustainable energy transitions. Appl Energy 228:624-632

Sareen S (2020) Metrics for an accountable energy transition? Legitimating the governance of solar uptake. Geoforum 114:30-39

Sareen S, Rommetveit K (2019) Smart gridlock? Challenging hegemonic framings of mitigation solutions and scalability. Environ Res Lett 14:075004

Sareen S, Saltelli A, Rommetveit K (2020) Ethics of quantification: illumination obfuscation and performative legitimation. Palgrave Commun 6(1):1-5

Schick L, Gad C (2015) Flexible and inflexible energy engagements-a study of the Danish Smart Grid Strategy. Energy Res Soc Sci 9:51-59

Schivelbusch W (1995) Disenchanted night: the industrialization of light in the nineteenth century. University of California Press, Berkeley

Shove E, Watson M, Spurling N (2015) Conceptualizing connections: energy demand, infrastructures and social practices. Eur J Soc Theory 18(3):274-287

Silvast A, Hänninen H, Hyysalo S (2013) Energy in society: energy systems and infrastructures in society. Sci Technol Stud 26(3):3-13

Silvast A, Williams R, Hyysalo S, Rommetveit K, Raab C (2018) Who 'uses' smart grids? The evolving nature of user representations in layered infrastructures. Sustainability 10(10):3738

Skjølsvold TM, Ryghaug M, Berker T (2015) A traveler's guide to smart grids and the social sciences. Energy Res Soc Sci 9:1-8

Stephens J, Wilson E, Peterson T, Meadowcroft J (2013) Getting smart? Climate change and the electric grid. Challenges 4(2):201-216

Stojkoska BLR, Trivodaliev KV (2017) A review of Internet of Things for smart home: challenges and solutions. J Clean Prod 140:1454-1464

Szulecki K (2018) Conceptualizing energy democracy. Environ Politics 27(1):21-41 Wolsink M (2012) The research agenda on social acceptance of distributed generation in smart grids: renewable as common pool resources. Renew Sustain Energy Rev 16(1):822-835

\section{Acknowledgements}

The author wishes to thank the Trond Mohn Foundation ('European cities in climate and energy transformation' project, grant BFS2016REK04), the Equinor-University of Bergen Akademia Agreement ('Energy transitions' project), the PARENT project (European Union Horizon 2020 grant agreement No. 857160 under the Joint Programming Initiative Urban Europe) and COST Action 16232 ENGAGER on European energy poverty for generous funding towards this research. He is grateful for helpful discussions with Nives DellaValle, Kjetil Rommetveit, Ingrid Ballo, Benjamin Sovacool, Frank Geels, Andrew Hook and Timothy Moss.

\section{Competing interests}

The author declares no competing interests.

\section{Additional information}

Correspondence and requests for materials should be addressed to S.S.

Reprints and permission information is available at http://www.nature.com/reprints

Publisher's note Springer Nature remains neutral with regard to jurisdictional claims in published maps and institutional affiliations.

Open Access This article is licensed under a Creative Commons Attribution 4.0 International License, which permits use, sharing, adaptation, distribution and reproduction in any medium or format, as long as you give appropriate credit to the original author(s) and the source, provide a link to the Creative Commons license, and indicate if changes were made. The images or other third party material in this article are included in the article's Creative Commons license, unless indicated otherwise in a credit line to the material. If material is not included in the article's Creative Commons license and your intended use is not permitted by statutory regulation or exceeds the permitted use, you will need to obtain permission directly from the copyright holder. To view a copy of this license, visit http://creativecommons.org/ licenses/by/4.0/

(C) The Author(s) 2020 